\title{
BIOPOLÍTICA, MÁQUINA ANTROPOLÓGICA E IDENTIDAD: AMÉRICA COMO UN ESPACIO LIBRE PARA LA VIOLENCIA
}

\author{
Lina ÁlVAREZ Villarreal* \\ doi:10.11144/Javeriana.uph32-65.bmai
}

\begin{abstract}
RESUMEN
El presente artículo realiza un análisis arqueológico de algunos de los discursos y prácticas que jugaron un rol decisivo en la efectuación de la Conquista de América y el establecimiento de un orden político fundado en un prejuicio racial, regido por la dominación y, en consecuencia, excluyente y violento. Dicha investigación se basa en: (i) los conceptos de biopolítica y máquina antropológica de Giorgio Agamben y la relación entre estos y las comunidades identitarias; (ii) los estudios de ciertos autores poscoloniales; y (iii) los escritos de Carl Schmitt sobre el derecho internacional. El análisis de la concepción aristotélico-tomista de lo humano, de la división geográfica del mundo construida desde Europa y de los tratados jurídicopolíticos celebrados entre soberanos europeos durante los siglos XV y XVI permitirán proponer a la Conquista de América como un paradigma de esta forma de poder que ha caracterizado la política de Occidente: la biopolítica.
\end{abstract}

Palabras clave: biopolítica; máquina antropológica; principio identitario;

Conquista de América; geografía

* Université Catholique de Louvain, Louvain-la-Neuve, Bélgica.

Correo electrónico: linaalvarezv@gmail.com

Para citar este artículo: Álvarez Villareal, L. (2015). Biopolítica, máquina antropológica e identidad: América como un espacio libre para la violencia. Universitas Philosophica, 32(65), pp. 107-136. ISSN 0120-5323, ISSN en línea: 2346-2426, doi:10.11144/ Javeriana.uph32-65.bmai 


\title{
BIOPOLITICS, ANTHROPOLOGICAL MACHINE AND IDENTITY: AMERICA AS A FREE SPACE FOR VIOLENCE
}

\author{
Lina Álvarez Villarreal
}

\begin{abstract}
This article presents an archaeological analysis of some of the discourses and practices that played a decisive role in the effectuation of the Conquest of America and the establishment of a political order based on a racial prejudice and domination. A political order that was, in consequence, extremely exclusionary and violent. This research is based (i) on the concepts of biopolitics and anthropological machine created by Giorgio Agamben, as well as on the relationship that exists between them and the communities founded on identitarian principles; (ii) the researches of post-colonial philosophers; and (iii) Carl Schmit's writings on International Law. The analysis of the Aristotelian-Thomistic conception of the human being, the geographical division of the World created from Europe, and the political treaties concluded between the emerging European States during fifteenth and sixteenth centuries, allow proposing the Conquest of America as a paradigmatic case of this form of power that has characterized Western politics: biopolitics.
\end{abstract}

Key words: biopolitics; anthropological machine; identitarian principle; Conquest of America; geography 


\section{Introducción}

En Thananmen, Giorgio Agamben señala la estrecha relación entre la construcción de una comunidad humana a partir de presupuestos identitarios y la biopolítica. Por su parte, en el Homo Sacer I -obra en la que Agamben desarrolla su concepto de biopolítica como forma de poder intrínsecamente ligada a la soberanía y cuyo objeto es la producción de nudas vidas- se hace referencia explícita a la producción de América como una zona de excepción; esto es, como un espacio libre y abandonado por el derecho que posibilitó el ejercicio de una violencia sin límites en esta parte del hemisferio. Sin embargo, el italiano no desarrolla este punto sino que se centra en las transformaciones de la biopolítica al interior de Europa. Las implicaciones de este pasaje han permanecido impensadas, de allí que el presente artículo pretenda prolongar este punto y poner en evidencia cómo la Conquista de América es un caso paradigmático ${ }^{1}$ que permite pensar la relación intrínseca entre Identidad, biopolítica y máquina antropológica.

Para esto, es necesario mostrar la forma como el poder soberano (ubicado en Europa), al decidir sobre situaciones excepcionales, construyó a América como un espacio libre de derecho, susceptible de ser apropiado y, simultáneamente, decidió sobre el momento y las características que permitieron que la vida de ciertos individuos dejara de ser políticamente relevante. Adicionalmente, es importante poner en evidencia la forma en que cierta concepción de lo humano estuvo a la base de saberes que posibilitaron la dominación de todo un continente. Cuatro discursos vigentes durante la Conquista manifiestan esto: (i) a nivel "intra-imperial" (decisiones que se emiten desde España hacia y contra los nuevos territorios americanos y sus habitantes, que son considerados como objetos de dominación) los discursos sobre la guerra justa de Juan Ginés de Sepúlveda, Bartolomé de Las Casas y Francisco de Vitoria; (ii) a nivel "inter-imperial" la filosofía aristotélica que estableció

1 Utilizo el término paradigmático en el sentido agambeneano, esto es, como el instrumento del cual se sirve la arqueología para construir un campo problemático y, al mismo tiempo, hacerlo inteligible (Agamben, 2009, p. 24). El paradigma se construye tomando un caso singular y apartándolo de su contexto habitual para así exhibir su singularidad y constituir un nuevo conjunto problemático. De esta manera, el trabajo mediante paradigmas permite alcanzar una arché, que no debe entenderse como "un origen presupuesto en el tiempo, sino que, al situarse en el cruce de diacronía y sincronía, vuelve inteligible no menos el presente del investigador que el pasado de su objeto" (Agamben, 2009, p. 43). 
al logos como lo propio del ser humano y que influyó en el desprecio de las prácticas indígenas, pues se veían como muy cercanas al cuerpo; (iii) la división del mundo en diferentes continentes efectuada en Europa desde la Antigüedad; y (iv) los tratados celebrados entre soberanos europeos para posibilitar la apropiación de los territorios americanos y el uso desmedido de la violencia en ellos. Este escrito se limita, debido a su naturaleza, a explicar el nivel "inter-imperial", sin profundizar en los discursos sobre la guerra justa.

Así, este artículo consta de tres partes: en la primera se exponen, brevemente, los conceptos de "biopolítica" y de "máquina antropológica" tal y como son pensados por Agamben, así como su relación con la construcción de comunidades desde presupuestos identitarios. En la segunda parte se muestra la forma como la concepción de lo humano construida durante siglos desde Europa terminó por producir una división jerárquica, excluyente y violenta de la humanidad, que se refleja en la valoración de las formas de vida de los indígenas americanos y, en general, de todos aquellos que habitaban fuera de lo que se conoce actualmente como Europa. En la tercera parte se pone en evidencia la forma como la máquina antropológica influyó en la constitución de un saber como la geografía existente para el siglo XV y XVI; también se muestra la forma como se construyó al "Nuevo Mundo" como un espacio libre para la dominación a través del acuerdo entre soberanos europeos. Finalmente, se da paso a algunas conclusiones.

\section{Biopolítica, máquina antropológica e identidad en Agamben}

El CONCEPTO DE BIOpolítica ha SUfRIDo una serie de desplazamientos semánticos desde su creación por parte de Rudolf Kjéllen (a finales del siglo XIX) hasta los desarrollos filosóficos que tomó en manos de autores como Michel Foucault, Giorgio Agamben, Antonio Negri y Roberto Esposito. Por esto se hace necesario determinar en qué sentido es empleado el término "biopolítica" en este artículo, esto es, el significado que toma en manos de Agamben y específicamente en su obra Homo Sacer. El poder soberano y la nuda vida (en adelante Homo Sacer I).

Agamben parte de las investigaciones de Foucault y comparte con él la concepción de la biopolítica como un poder que se ejerce sobre la vida, entendida como zoé y no como bios; es decir, un poder que se interesa por la vida como dato 
biológico. Sin embargo, distanciándose del proceder foucaultiano, que evitaba el estudio del poder desde modelos jurídico-institucionales, el italiano construye en el Homo sacer I el problema biopolítico a partir del concepto institucional por excelencia: la soberanía. Con el ánimo de mostrar la relación entre soberanía y vida biológica o zoé, Agamben se apoya en los estudios de Carl Schmitt, quien en su Teología política, afirma que la soberanía debe definirse desde su concepto límite, esto es, desde el soberano como aquél que tiene la facultad de decidir si un caso es o no de necesidad y si debe suspenderse el ordenamiento legal e incluso el constitucional. Así, Agamben concluye que la soberanía remite a un poder que se sitúa fuera del ordenamiento jurídico, porque en este no se encuentra pre-determinado cuáles serán los casos excepcionales o de necesidad, ni las medidas específicas que deben ser tomadas en dichas situaciones; no obstante, al mismo tiempo -y es en este punto donde el italiano se aparta del decisionismo de Schmitt- la soberanía está dentro del ordenamiento porque el derecho mismo faculta al soberano para inaplicarlo. La estructura, entonces, de la soberanía radica en la excepción (Ausnahme), pues soberano es aquel capaz de decidir qué es lo excepcional, qué puede sustraerse a los casos normales a los que, en tanto tales, puede y debe aplicárseles el derecho (Agamben, 2010, p. 28).

Para Agamben la estructura de la soberanía es la de una decisión sobre la excepción, o lo que es lo mismo, es la exclusión de un caso respecto a la norma, en donde aquel (el caso) se mantiene en relación con esta (la norma) a través de la violencia generada por la suspensión de la vigencia de la ley. En otras palabras, debido a la decisión del soberano, el ordenamiento se retira o se sustrae de un caso o hecho determinado, configurando la excepción e incluyendo, de esa forma, el exceso en una relación donde la violencia es la que posibilita la relación misma. A esta relación "que solo incluye algo a través de su exclusión" Agamben la denomina relación de excepción (2010, p. 31). La diferencia, entonces, entre la comprensión de la soberanía como aquello que busca interiorizar el afuera a través de un "cercamiento" (el grand enfermement de Foucault, por ejemplo) y la afirmación de que la soberanía es, sobre todo, una relación de excepción radica, fundamentalmente, en que la excepción soberana no busca tanto controlar como "definir el espacio mismo en que el ordenamiento jurídico-político puede tener valor” (Agamben, 2010, p. 31). Esto quiere decir que para Agamben la decisión soberana, al dejar en relación de excepción al afuera, lo interioriza no para normalizarlo sino para abandonarlo y 
dejarlo expuesto a una violencia no regulada. A partir de este tipo de decisión el soberano produce vidas que pueden ser aniquiladas con total impunidad y sin sacrificio, vidas que Agamben llama nudas vidas y que constituyen el segundo elemento de la biopolítica. Es por esto que, para Agamben, los sujetos de derecho no sufren la soberanía; esta es ejercida, subrepticiamente, sobre una nuda vida, que es excluida al ser expuesta a la violencia y a la decisión soberana (Genel, 2004). En breve, para Agamben la biopolítica está constituida por dos elementos: una decisión soberana y una nuda vida.

La relación entre poder soberano y nuda vida establecida por Agamben, ha provocado que diversos académicos afirmen que en el Homo Sacer I se presenta un concepto de biopolítica en donde el ingreso de la vida biológica en la política no se da para hacerla productiva, sino para posibilitar su aniquilación ${ }^{2}$. Aún cuando esto es cierto, solo lo es hasta cierto punto. Y es que la interpretación que hace Agamben de la soberanía lo lleva a reconocer un carácter positivo o productivo de la biopolítica al menos en tres aspectos: (i) produce nudas vidas; (ii) establece nuevos ordenamiento jurídicosy territoriales, asícomo formas de organización sociales (Agamben, 2010, p. 32); y (iii) al politizar la nuda vida, la biopolítica "decide acerca de la humanidad del ser vivo hombre" (Agamben, 2010, p. 18). En otras palabras, la situación de suspensión producida por el poder soberano no es meramente negativa sino productiva, pues crea el derecho, crea un nomos que es, a la vez, ocupación y división. Para explicar la relación soberanía-derecho y, específicamente, la necesidad que tiene el derecho de la excepción, Agamben recurre a una analogía con la teología negativa que es explicada en los siguientes términos: "la teología negativa con su ni... ni..., niega y suspende cualquier predicación. No está sin embargo, fuera de la teología, sino que, bien visto, funciona como el principio que funda la posibilidad general de algo como una teología" (Agamben, 2010, p. 30). Es así como el italiano retoma los dos efectos reales que produce la soberanía señalados en el Nomos de la tierra de Schmitt; esto es, que ella efectúa una ocupación de la tierra (Landnahme) y la fijación de un orden jurídico (Ordung) y territorial (Agamben, 2010, p. 32), y agrega que el nomos soberano no se limita a ocupar un territorio y a trazar la distancia entre el caos y lo normal, sino que en la ocupación del afuera se produce un espacio libre de derecho pero

2 Al respecto, véase: Lemke, 2005, p. 8. 
que mantiene su relación con este porque ha sido abandonado: zona ilocalizable de indiferencia o excepción (Agamben, 2010, p. 32). Como se ve, la comprensión de la biopolítica de Agamben como una forma de poder tiene un alto carácter tanato-político, pero también un elemento productivo (de lo jurídico e, igualmente, de un orden territorial o de lo que puede ser considerado como propiamente humano) que es fundamental para comprender la manera como la máquina imperial funcionó en la Conquista de América, pues el proceso colonizador no se limitó a aniquilar poblaciones enteras, sino a instaurar un nuevo orden social, político y económico en favor de las potencias europeas.

La nueva concepción de la biopolítica lleva a Agamben a afirmar que esta no es una forma de poder propia del siglo XVIII (como lo había afirmado Foucault), sino que "es tan antigua al menos como el poder soberano" (Agamben, 2010, p. 16). Por ello rastrea su origen en dos ámbitos diferentes: uno que podríamos llamar "conceptual-metafísico" que, a partir de la escisión originaria de la vida entre zoé y bios, da al pensamiento las categorías necesarias para pensar la política, y que Agamben ubica en el pensamiento de Aristóteles; otro que podríamos denominar "político-jurídico", en donde efectivamente se ejerce la soberanía, y que Agamben rastrea en el homo sacer, se trata de una figura del derecho romano arcaico definida por el historiador romano Festo de la siguiente forma: "aquel a quien el pueblo ha juzgado por un delito, no es lícito sacrificarle, pero quien le mate, no será condenado por homicidio" (Festo citado por Agamben, 2010, p. 94). El homo sacer es, entonces, aquel en donde se yuxtaponen dos características: "la impunidad de darle la muerte y la probibición de su sacrificio" (Agamben, 2010, p. 96). Como se mostrará en los siguientes apartes, la interpretación de la Conquista de América como un evento biopolítico es de gran interés para la filosofía política, pues allí estos dos ámbitos se confunden y una nueva emergencia o giro en el uso del poder biopolítico tiene lugar. Al tiempo que los discursos sobre los indígenas producen una división de la vida en zoé y bios que termina por construir el imaginario de la inferioridad de estos pueblos, los poderes soberanos europeos emiten decisiones que garantizan la dominación de los "nuevos" territorios y las jerarquías al interior de la humanidad.

Por otra parte, es importante aclarar la relación directa que Agamben establece entre biopolítica y máquina antropológica o producción de lo humano, a pesar de que esto último no se limite al ámbito de la soberanía estatal sino que lo 
excede. Según el italiano, la biopolítica opera a través de la determinación de lo que se considera humano y la exclusión de lo que se asume como inhumano, señalando un ideal de humanidad que intenta acallar la vida como tal. Es esa la separación a la que, en últimas, se refiere Agamben cuando habla de división entre zoé y bios. De allí que la noción de máquina antropológica sea fundamental para comprender su propuesta biopolítica, concepto que es desarrollado en Lo Abierto, una obra posterior al Homo Sacer I. Agamben llama máquina antropológica a la operación que decide sobre la separación y la articulación entre lo humano y lo animal; decisión que no es tomada de manera definitiva sino que siempre está en curso de ser tomada. Así, este concepto no designa una esencia o un contenido propio a lo humano, que cambiaría en el curso de la historia, sino la puesta en marcha de un dispositivo que, de manera estratégica, no cesa de producir lo humano y desplazar sus límites a través de la división entre la vida cualificada de los humanos y la vida no-humana, división que se efectúa no solamente entre los diferentes vivientes sino, sobre todo, al interior de la humanidad. Nuevamente, el italiano ubica en Aristóteles el origen de esta división, y a partir de él rastrea la manera como los discursos en Occidente han definido lo humano. Así, la arqueología que Agamben realiza desde Aristóteles pasando por Tomás de Aquino, Lineo y Heidegger, lo lleva a concluir que la ontología no es un discurso inofensivo, sino "la operación en todo sentido fundamental en la que se realiza la antropogénesis, el devenir humano del viviente” (Agamben, 2006, p. 145). Esta conclusión se liga a esta otra: "el conflicto político decisivo, que gobierna todo otro conflicto es, en nuestra cultura, el conflicto entre la animalidad y la humanidad del hombre" (Agamben, 2006, p. 146). De esta forma, se hace evidente el carácter intrínsecamente violento de la máquina antropológica, pues al naturalizar determinadas características como propias o esenciales del ser humano, se terminan excluyendo formas de vida según una decisión soberana que no deja de desplazar los límites entre el hombre y el animal. Por las mismas razones, las cesuras producidas al interior de la vida terminan configurando órdenes jerárquicos y relaciones de dominación entre humanos.

Finalmente, para los objetivos de este artículo es importante señalar la relación que Agamben establece entre identidad, poder soberano y nuda vida. En Tiananmen, el autor sostiene que la política ha estado estrechamente ligada al problema del Estado y, en consecuencia, a la identidad. Esto genera un ámbito de 
exclusión, una zona de desprotección en la que se encuentran aquellos que no cumplen con determinadas condiciones. En otras palabras, Agamben muestra que el poder soberano se construye a partir de presupuestos identitarios; esto es, que para entrar y ser reconocido en el ámbito de lo político, el Estado siempre exige ser parte de esto o de aquello: hablar determinada lengua, operar bajo ciertos principios epistemológicos, tener determinadas creencias, estar bajo determinado tipo de gobierno, cumplir con determinadas características biológicas, etcétera. Esta exigencia, el deber ser o reconocerse como algo o alguien para acceder a la protección política y jurídica, necesariamente produce una exclusión, pues quienes no cumplan con las condiciones quedan desprotegidos, y por consecuencia se produce una nuda vida. Así, la identidad se configura como un elemento esencial de la biopolítica, en tanto juega un papel fundamental en la producción de nudas vidas, de zonas de indiferencia entre el afuera del derecho y lo político (physis o estado de naturaleza) y su interior (nomos o estado civil).

Laura Quintana, al analizar el pensamiento de Agamben, ha explicado la relación entre la biopolítica y la concepción de la comunidad humana en términos de identidad de la siguiente manera:

si la política siempre se ha fundado sobre el supuesto de una nuda vida, ello tendría que ver con el hecho de que, a lo largo del pensamiento occidental, la vida-en-común de los hombres siempre se habría pensado en términos de identidad, es decir, en términos de inclusión, de pertenencia a una vida, a un bios en el que los hombres tendrían que poder realizarse como tales. (...) Así, desde los planteamientos de Agamben, no sólo el derecho necesita para su propia vigencia de la excepción, sino que toda comunidad política que se defina en términos de pertenencia supone la relación de excepción y, por ende, supone la consideración de otras vidas como nudas vidas. (Quintana, 2006, p. 53)

En conclusión, es posible decir que máquina antropológica y biopolítica están estrechamente ligadas, pues aquella opera a partir de la lógica exclusión-inclusión de lo humano y lo animal, produciendo un espacio vacío ocupado únicamente por una nuda vida. En ambos casos la estructura es la de la soberanía (una decisión sobre la excepción), y recaen sobre el mismo objeto: la vida. El carácter violento y aporético de estos dos dispositivos es claro, pues al establecer lo que debe ser protegido (el ser humano), se produce un resto (animalidad o zoé) que es 
abandonado y expuesto a toda violencia. Con más precisión, la máquina antropológica es una efectuación de la biopolítica en la medida en que, por un lado, la determinación de lo humano establece los límites entre lo humano y lo no-humano y al interior de la humanidad, y por otro, dicha delimitación determina qué debe ser protegido por la política y qué debe ser excluido para que quede expuesto a una violencia no regulada y que quedará impune. $\mathrm{Al}$ mismo tiempo, la política se sirve de esta distinción entre lo humano y lo animal para producir, por medio de una decisión soberana, nudas vidas.

Partiendo de los conceptos agambeneanos, el presente artículo aspira develar el funcionamiento de esta máquina y de la biopolítica en uno de los eventos más importantes y violentos de nuestra historia: la Conquista de América; evento privilegiado para comprender la simbiosis entre las dos máquinas, porque las decisiones y justificaciones jurídico-soberanas que convirtieron a América en espacio libre para la violencia se apoyaron en la filosofía aristotélico-tomista que contenía una concepción determinada de lo humano. La Conquista de América constituye un paradigma de la relación identidad-producción de nudas vidas-máquina antropológica, pues la división del mundo a través de acuerdos entre soberanos europeos, la apropiación de los territorios americanos y la aniquilación y explotación de los indígenas, fueron posibles gracias a la idea de que Europa y los hombres que habitaban allí, por tener determinadas costumbres y creencias, eran mejores que el resto de los seres humanos. Es momento de analizar, con mayor detalle, la construcción europea de lo humano en los siglos XV y XVI y la forma como ella influyó en la producción de saberes que tuvieron una injerencia en la política y en las decisiones soberanas durante la Conquista.

\section{La afirmación de la identidad europea a partir del logos y la pretendida inferioridad de los indígenas}

EN LA OBRA DEL HOMBRE, AgAMBEN eXPONe la tesis según la cual las categorías metafísico-conceptuales que permitieron el desarrollo de la biopolítica emerge en el momento mismo en que Aristóteles apuesta por una naturaleza humana, pues esta se define mediante la exclusión de un tipo de vida que se asume como no cualificada -zoé- para determinar, a partir de esa definición, la política y la felicidad de los hombres (Agamben, 2007, p. 466). Esta misma tesis se encuentra en 
las primeras páginas del Homo Sacer I, cuando Agamben formula como objetivo del libro mostrar la relación intrínseca entre la estructura del poder soberano (la decisión sobre la excepción) y la biopolítica (Agamben, 2010, pp. 16-17). El autor italiano recurre a la forma como Aristóteles resuelve el problema de si el hombre en cuanto ser genérico tiene una obra (érgon) que le pertenezca en cuanto tal; es decir, si según su naturaleza le viene una obra, pues así como al zapatero le corresponde hacer zapatos, al carpintero hacer muebles, al ojo ver y al oído oír, cabe también preguntarse por la obra del ser humano ya no cuando se ocupa de hacer esto o aquello, sino como miembro de la especie humana. La comprensión de la solución dada por el Estagirita a este problema es indispensable para un análisis de la biopolítica en el siglo XVI y de los discursos que justificaron la Conquista de América, puesto que las nociones de humano y de bárbaro dadas por este filósofo son empleadas para determinar la naturaleza del indígena y el consecuente trato que se les debía otorgar.

Aristóteles encuentra que el érgon de los hombres está en el ámbito de la vida, y afirma que la obra propia del hombre es el logos que corresponde a un tipo de vida práctica y racional (praktiké tis). Esto se justifica a través de la relación del ser humano con el resto de los vivientes, animales y plantas, dividiéndolos y creando una jerarquía en la zoé. Así, el filósofo afirma que el ser humano comparte la vida nutritiva con animales y plantas y la sensitiva con los animales, de modo que lo que lo diferencia es el hecho de tener logos (Agamben, 2007, p. 468). De esta forma, Agamben muestra que los griegos conciben la política como intrínsecamente relacionada con la vida, relación que califica de "aporética", pues la política es establecida como el lugar donde la zoé no debe dejar de dividirse y, al mismo tiempo, de articularse. En efecto, los hombres solo pueden hacer parte de la polis a condición de apartar su nuda vida o vida biológica y dejarla relegada en el ámbito de la casa, es decir, en el ámbito "privado", por lo que la zoé no es completamente excluida o suprimida; al mismo tiempo, los hombres deben conservar el logos que se considera como lo propio del espacio público (Agamben, 2010, p. 17). En consecuencia, la política se funda a partir de la exclusión de ciertas formas de vida, pues la obra del hombre es "en último término «una cierta vida», que se define ante todo por la exclusión del simple hecho de vivir, de la vida desnuda” (Agamben, 2007, p. 472), esa cierta vida es la vida según el logos (Agamben, 2007, p. 470). 
A partir de allí una jerarquía entre los seres queda establecida, ocupando el lugar más bajo las plantas, en seguida los animales y, en el lugar más alto, los humanos. Diecisiete siglos después, el Doctor Angélico reformularía esta gradación de la vida - y, por lo tanto, de los seres - al servicio del cristianismo en los siguientes términos: "[n]o falta orden en la producción de las cosas, pero no el de que una criatura sea producida por otra, lo cual es imposible, sino el orden establecido por la divina sabiduría al instituir diversos grados en las criaturas" (Aquino, 1950, p. 773). Dicha jerarquía no opera solo entre las diferentes especies sino al interior de los hombres, en virtud de un principio único y trascendente: el logos. En realidad, Aristóteles no es el primero en afirmar la preeminencia del logos en el hombre, ya esto lo había hecho Platón al someter el cuerpo al alma y al afirmar que la parte concupiscente del alma debía ser dirigida por la racional. Esta jerarquía en el ser humano se traducía en una distribución política: los agricultores y artesanos en el lugar más bajo, a continuación los guerreros y, finalmente, los hombres políticos que, en Platón, son los filósofos (Leyes 737e-747e). Como es conocido, el Cristianismo adopta estas tesis y hace las modificaciones necesarias para que sean compatibles con sus dogmas, produciendo la idea de un menosprecio del cuerpo (que no estaba presente en el pensamiento de Platón) y la importancia de llevar una vida ascética dirigida por la virtud.

La concepción griega de lo humano y sus posteriores reapropiaciones por el pensamiento cristiano terminaron por contribuir a la constitución de un orden racista a raíz del encuentro con América, en el que operaban las máquinas antropológica y biopolítica. En efecto, durante la Conquista, aquellos que no cumplían con determinada identidad fueron excluidos de la comunidad política y su vida convertida en nuda vida. Como lo han mostrado las investigaciones de diversos académicos, la idea de Europa como el lugar ideal para la realización plena de la vida humana, que hace parte de un prejuicio racial, se encuentra a la base de los discursos que posibilitaron la distribución de la tierra a favor de los reinos europeos. Así, autores con perspectivas políticas y filosóficas tan disímiles como Carl Schmitt, Walter Mignolo, Lewis Hanke y Edmundo O'Gorman coinciden en afirmar que la Conquista de América se realizó bajo el presupuesto de la superioridad de los europeos y la correlativa inferioridad de los indígenas. Según Schmitt, los "nuevos" territorios no fueron concebidos por los europeos como "un nuevo enemigo, sino como un espacio libre, como un campo libre para la 
ocupación y expansión europea" (Schmitt, 2002, p. 55), y el autor señala que el ordenamiento jurídico que se construyó a lo largo del siglo XVI refleja esa imagen de superioridad europea:

El Derecho de Gentes europeo de la época de los siglos XVI al XX consideraba a las naciones cristianas de Europa como creadoras y portadoras de una ordenación que era válida para toda la tierra. «Europeo» designaba entonces el status normal, que también reclamaba ser normativo para la parte no europea de la tierra. El término civilización era equivalente a civilización europea. (Schmitt, 2002, p. 54)

De manera similar a Schmitt, aunque bajo presupuestos y con pretensiones muy diferentes, Walter Mignolo afirma, en La idea de América, con respecto a la concepción de los europeos sobre el nuevo continente que:

Es cierto que los autores [europeos desde Las Casas a Hegel] reconocen que hay un mundo y unos pueblos fuera de Europa, pero también es cierto que ven a esos pueblos y a los continentes en que habitan como «objetos», no como sujetos, y en cierta medida, los dejan fuera de la historia. Dicho de otra forma, se trata de sujetos cuyas perspectivas no cuentan. (Mignolo, 2007, p. 17)

El elemento identitario de la biopolítica en el siglo XVI se hizo evidente con toda su fuerza, puesto que las potencias europeas configuraron su poder y justificaron la adquisición de la tierra con base en la determinación de lo humano que exige separar la zoé e instituir el dominio del logos. Esta distinción permitió, por un lado, calificar a los indígenas como bárbaros, susceptibles de explotación, de ser evangelizados o de ser objeto de muerte con impunidad; por otro, construir al continente americano como territorio de nadie, susceptible de ser anexado a los reinos europeos. Para Mignolo, la posibilidad de aniquilar vidas y creencias, de restarles importancia y asignarles determinados roles, requirió de la definición de lo humano a partir de un determinado centro y de la construcción de un tipo de racismo:

Para que una historia sea vista como la primordial, debe existir un sistema clasificatorio que favorezca la marginación de determinados conocimientos, lenguas y personas. Por lo tanto, la colonización y la justificación para la apropiación de la tierra y la explotación de la mano de obra en el proceso de invención de América requirieron la construcción ideológica del racismo. La introducción de los indios en la mentalidad europea, la expulsión de los moros y judíos de 
la península ibérica a finales del siglo XV y la redefinición de los negros africanos como esclavos dio lugar a una clasificación y categorización específica de la humanidad. (Mignolo, 2007, pp. 40-41, las cursivas son mías)

Respecto al término "raza" empleado en este contexto, el filósofo argentino aclara:

$[\mathrm{L}]$ a cuestión de la «raza» no se relaciona con el color de la piel o la pureza de la sangre sino con la categorización de individuos según su nivel de similitud o cercanía respecto de un modelo presupuesto de humanidad ideal. La noción de «raza» sería similar a la de «etnia», pues la raza se refiere a la genealogía sanguínea, genotípica o de color de la piel y la etnia incluye la lengua, la memoria y un conjunto de experiencias compartidas pasadas y presentes, por lo que comprende un sentido cultural de comunidad, lo que las personas tienen en común. (Mignolo, 2007, p. 42)

El racismo, entonces, tal y como es definido por Mignolo, implica la constitución de una comunidad en virtud de determinados rasgos que se comparten y se asumen como modelo y que pueden ir de la lengua y la religión hasta el color de la piel y una pretendida combinación única de genes homocigóticos. La construcción imaginaria de la idea de la superioridad de dicha comunidad lleva a una exclusión de otras formas de vida y, en consecuencia, configura una biopolítica. Esto no implica que toda biopolítica implique un racismo, aunque sí es posible afirmar, desde Agamben, que en todo racismo opera una biopolítica. Además, el hecho de que la discriminación se configure a partir de un modelo de lo humano, deja ver la operación de una máquina antropológica en términos agambeneanos.

Si bien, durante la Conquista el racismo no se configuró exclusivamente por una decisión soberana-imperial, las decisiones que tomaron los monarcas europeos sí estaban fundadas y atravesadas por esa concepción racial de la humanidad, por una máquina antropológica logocentrista y eurocéntrica. En efecto, en los diferentes discursos y leyes de la época se capta cómo está latente la descalificación de las formas de vida de los llamados americani, debido a la diferencia que estos hombres representan.

Las Crónicas de las Indias ponen en evidencia el menosprecio por parte de los europeos frente a formas de vida de los habitantes americanos por considerar que estaban guiadas por lo corporal y las pasiones y, en consecuencia, que se encontraban más cerca de lo animal que de lo propiamente humano. Ejemplo de esto son los relatos de Tomás Ortiz: 
Estas son las propiedades de los indios por donde no merecen libertades comen carne humana en la tierra firme; son sodométicos más que generación alguna, ninguna justicia hay entre ellos: andan desnudos: no tienen amor ni vergüenza; son estólidos y alocados (...) son bestiales y preciánse de ser abominables en vicios: ninguna obediencia ni cortesía tienen mozos a viejos, ni hijos a padres (...) inimicísimos de religión (...) No se guardan lealtad maridos a mujeres, ni mujeres a maridos. Son echiceros y augureros y covardes como liebres. Son sucios: comen piojos y arañas y gusanos crudos doquiera que los hallan (...) son sin asnos, y no tienen en nada matarse. (Jáuregui, 2008, p. 98)

Incluso, cuando los europeos se refieren a los indígenas expresando una especie de admiración por su organización, lo hacen presuponiendo que viven en un estado idílico por su falta de desarrollo, como lo señalan algunas cartas de Colón (Rojas, 2007, p. 141). De manera similar, las teorías de la guerra justa de Vitoria, Las Casas y Sepúlveda ponen en evidencia la importancia que tuvo la definición de lo humano a partir del logos en la Conquista de América. En efecto, las prácticas antropófagas, el homosexualismo, la inexistencia del matrimonio, la ausencia del cristianismo, entre otros, fueron empleados como argumentos para identificar a los indios como bárbaros, casi animales, y afirmar la conveniencia para estos de ser gobernados por los españoles, así como la justificación del uso de la fuerza en su contra ${ }^{3}$. Por ejemplo, Sepúlveda afirma la superioridad natural de los españoles (por lo tanto su tendencia natural a gobernar) y la correlativa inferioridad natural de los indígenas (por lo tanto su tendencia natural a ser gobernados) que se manifiesta en las prácticas "irracionales" o "bárbaras; esto es, en la corrupción de la facultad propia del hombre: la razón. Sus palabras son:

Compara ahora estas dotes de prudencia, ingenio, magnanimidad, templanza, humanidad y religión [de los españoles] con la de estos hombrecillos [los indigenas americanos] en los que apenas se pueden encontrar restos de humanidad, que no sólo carecen de cultura, sino que ni siquiera usan o conocen las letras ni

3 Véase, por ejemplo, la Relección sobre los indios, de Vitoria (1946, p. 49) donde se reconoce la capacidad racional de los indios y, al tiempo, se afirma su escaso desarrollo o estado de corrupción debido a los sacrificios que practican. También, la Apología, de Las Casas, (1988, pp. 140-141) donde se afirma que la no pertenencia al Cristianismo constituye el caso más grave de barbarie y en el caso de los indígenas produce la obligación de los españoles de evangelizarlos (aunque no de hacer uso de la fuerza física). 
conservan monumentos de su historia (...) ¿Qué se va a esperar de hombres entregados a toda clase de pasiones y nefandas liviandades y no pocos dados a alimentarse de carne humana? (...) se hacían la guerra casi continuamente entre sí con tanta rabia que consideraban nula la victoria si no saciaban su hambre prodigiosa con las carnes de sus enemigos. (Sepúlveda, 1951, p. 35)

Es así como los discursos que afirman la identidad y superioridad de los individuos que pertenecen a Europa y que definen lo humano en virtud de determinados principios, fueron capturados por las potencias imperiales del siglo XVI para ponerlos a funcionar dentro de su propia lógica y en favor de sus intereses. El poder soberano se sirvió de los prejuicios raciales y excluyentes construidos durante siglos en los discursos filosóficos, reproduciéndolos y modificándolos para alcanzar, por ejemplo, la adquisición de territorios, la mano de obra, los metales preciosos, entre otros. $\mathrm{Al}$ mismo tiempo, esos discursos y decisiones soberanas terminaron por afectar el ámbito de las prácticas localizadas (regímenes de plantación, instituciones como la encomienda y la esclavitud, políticas de blanqueamiento, son ejemplos de la forma como las decisiones soberanas terminaron por construir prácticas racistas en las colonias). Debido a los límites y pretensiones de este artículo, no se hará referencia a la forma como la filosofía aristotélico-tomista fue empleada para justificar la guerra contra los indios americanos en el marco de las teorías de la guerra justa, sino que se mostrará la forma como la concepción esencialista de lo humano ayudó a configurar una geografía discriminatoria y la celebración de tratados que legitimaban el uso desmedido de la fuerza en América.

\section{La geografía como biopolítica}

TAnto O'Gorman como Mignolo se han dedicado a pensar el surgimiento y las implicaciones de las expresiones "Descubrimiento de América" y "Nuevo Mundo", y concluyen que América, como el continente que conocemos hoy en día, es una entidad que no existió siempre, sino que surgió a partir del encuentro con Europa y fue construida desde el imaginario y cosmovisión europeos. Los resultados que arrojan las investigaciones de O'Gorman y Mignolo que se encuentran recogidos, sobre todo, en La invención de América y La idea de América respectivamente, son de fundamental importancia para la comprensión de la 
construcción de una biopolítica en la Conquista de América y su relación con la identidad que se había venido construyendo desde hace siglos en Europa. Centrarse en el tema de la geografía o división del mundo por parte de los europeos con anterioridad a la llegada de Cristóbal Colón a América, tema abordado por los dos autores, permite entender bajo qué presupuestos (que implican una jerarquía al interior del género humano), en el siglo XVI, los españoles, portugueses, ingleses y franceses efectuaron una división de la tierra y llevaron a cabo la dominación sobre los "nuevos" territorios.

La construcción de América como un cuarto continente cuyo destino era ser "asistido" por las potencias europeas para que alcanzara el mismo nivel de desarrollo, no debe ser leído como el resultado de una invención azarosa y espontánea de la época; tampoco como un proyecto meramente económico por parte de los europeos, que solo habrían buscado la explotación económica per se de los nuevos territorios. Todo lo sucedido en la Conquista y a partir de ella es consecuencia de una visión del mundo concreta y de una concepción de lo político que, como se ha venido señalando, tiene orígenes que se ubican con anterioridad del siglo $\mathrm{XV}$ :

Es importante comprender que dicha imagen [la imagen de la realidad que tenian los europeos en el siglo $X V$ ] no representa una visión estática arbitraria o errónea, como suele pensarse, sino el estadio que había alcanzado a finales del siglo XV el proceso multisecular de los esfuerzos que venía desplegando el hombre de Occidente por entender su sitio y su papel en el cosmos. (O’Gorman, 1995, p. 57)

Es cierto que en la Conquista y durante la colonización de América estaban en juego intereses económicos; sin embargo, estos no fueron los únicos motores de esta gran empresa. En ella convergieron elementos heterogéneos como la religión y los intereses políticos por conducir a los indios hacia lo que los europeos consideraban que era el mejor estado de la humanidad. En otras palabras, al nivel voluntario y consciente, no todos los españoles y portugueses y no todas sus instituciones estaban encaminadas a explotar a los indios y erradicarlos sin preocuparse por su destino. De allí que O'Gorman (1995) afirme:

efectivamente, en lugar de deshacerse del indio o simplemente utilizarlo sin mayor preocupación que la del rendimiento de su trabajo, España intentó de buena fe -pese al alud de críticas que se le han hecho- incorporarlo por medio de leyes e instituciones que, como la encomienda, estaban calculadas 
para cimentar una convivencia que, en principio acabaría por asimilarlo y en el límite, igualarlo al europeo. (p. 154)

Pero, en un nivel más profundo, encontramos que ese interés por salvar a los indios implicaba su destrucción, pues se les exigía ser como el hombre europeo. Es, precisamente, este el punto que resulta preocupante e interesante para una investigación filosófica ya que envuelve una de las paradojas más fuertes de la política como ha sido pensada en Occidente y señalada por Agamben, a saber: que la protección y realización de la vida exige, a su vez, su aniquilamiento. Un análisis de la Conquista puede entonces ayudarnos a develar los problemas intrínsecos de una política de la identidad que llevan a una biopolítica. ¿Cuáles son esos elementos heterogéneos que construyeron el imaginario europeo y su cosmovisión y cómo se forjaron para que llegaran a producir una forma tan violenta de ejercer el poder como lo fue la Conquista y la Colonia? Así como la determinación aristotélica del hombre implica un problema biopolítico, la concepción de la geografía está también relacionada con la categorización racial y la biopolítica del siglo XVI. Veamos cómo este saber juega un papel estratégico en la nueva configuración del poder.

La forma de la Tierra, la distribución entre mares y zona terrestre, y la existencia de una extensión de tierra diferente a lo que actualmente se conoce como Asia, Europa y África fueron, desde la Grecia Antigua, problemas que ocuparon la mente de los pensadores europeos. Para el siglo XV la tesis de que la zona terrestre era una gran isla (llamada orbis terrarum) rodeada de agua había terminado por imponerse sobre las más variadas hipótesis (O’Gorman, 1995, pp. 61-62), pero, al mismo tiempo, persistía la duda de si existían otras islas habitadas por seres humanos (las denominadas "Antípodas" u orbis alterius). Para los paganos de la Antigüedad no hubo problema en formular la existencia de las Antipodas, a las que ubicaron en el hemisferio sur y consideraron como habitada por un tipo diferente de hombres, como lo muestra el De situ orbis del geógrafo romano Pomponio Mela (O’Gorman, 1995, p. 62). Sin embargo, con la llegada del Cristianismo, estas tesis resultaron inaceptables por dos razones: en primer lugar, porque al aceptar que los habitantes de ese desconocido continente eran hombres de diferente tipo, se iría en contra del dogma cristiano de que la humanidad desciende de Adán y Eva exclusivamente; en segundo lugar, porque, de existir, esos hombres no conocerían la palabra de Dios, lo cual implicaba un problema 
de cara a las Sagradas Escrituras, que afirman que la palabra de Dios fue llevada a todos los rincones del mundo (O’Gorman, 1995, p. 62). De allí que Agustín de Hipona negara la existencia de tales regiones y afirmara que, en caso de que las hubiera, debían estar inhabitadas (Agustín, 1988, p. 249).

Durante la Edad Media estas dos posturas fueron debatidas pero, incluso en los casos en que se sostiene que habría extensiones de tierra más allá de Europa, Asia y África, se afirmaba que ellas estarían inhabitadas, como lo sostenía San Isidoro de Sevilla (O’Gorman, 1995, p. 62). Este último punto es importante para este trabajo porque constituye el "antecedente conceptual de la polémica acerca de la humanidad o no del indio americano" (O’Gorman, 1995, p. 169). Como sabemos, rápidamente se reconoció que los indios tenían alma humana, pero esto no implicó la igualdad frente a los europeos. La ya existente jerarquía entre europeos, africanos y asiáticos, producto de una interpretación de los griegos y de la reapropiación de esa tesis desde las Sagradas Escrituras por el Cristianismo, dio lugar al ingreso de los americanos en esa escala de la humanidad.

Esta jerarquía empieza a conformarse desde que Heródoto cuenta que hacia el siglo VI a.C. el mundo había sido dividido en tres grandes partes por el historiador y geógrafo Hecateo: Europa, Asia y Libia (actual África) (O’Gorman, 1995, p. 147). Esta distribución implicaba una jerarquía al interior de la humanidad, pues se pensaba que Europa era la parte más perfecta de las tres porque reunía las características idóneas para el desarrollo pleno de la vida humana (O'Gorman, 1995, p. 147). Posteriormente, en ese extraño sincretismo que caracteriza al Cristianismo, el mundo como morada de los hombres fue dividido en tres partes, cada una correspondiente a un hijo de Noé: Asia correspondía a Sem; África, a Cam, y Europa, a Jafet (Mignolo, 2007, p. 48; O'Gorman, 1995, p. 76; San Agustín, 1988, pp. 243, 270). Nuevamente, la división tripartita de la Tierra "estructuraba en un orden jerárquico ascendente a África, Asia y Europa, esta última la más perfecta por su naturaleza y espiritualmente privilegiada” por estar fundada sobre la fe cristiana y el misterio de la Redención (O’Gorman, 1995, pp. 76, 148).

En esta forma, la división geográfica del mundo realizada desde Europa terminó por configurar una forma de ejercer el poder excluyente: todo aquello que estuviera allende las fronteras territoriales y culturales de Europa era valorado como inferior; en consecuencia, para acceder al reconocimiento europeo era necesario 
asimilarse a ese modelo y eliminar las diferencias. Así, O'Gorman (1995) sostiene que con el Cristianismo "Europa asume la historia universal, y los valores y las creencias de la civilización europea se ofrecen como paradigma histórico y norma suprema para enjuiciar y valorar las demás civilizaciones. Tal es el sentido moral y cultural de la estructura jerárquica de la división tripartita del mundo" (p. 148).

Es en este contexto que se da el encuentro de los europeos con los territorios americanos. Para la comprensión de la formación de una biopolítica en la Conquista de América es relevante examinar la forma como fueron incorporados los nuevos territorios a esta visión geográfica y teológica del mundo. De cara a la mencionada división del mundo a partir de la Biblia, que se consideraba el libro que contenía la verdad revelada, la aparición de un cuarto continente no mencionado debió haber resultado, cuando menos, incómoda. Como ya se dijo, en un primer momento se dudó acerca de la humanidad de los indios, pero este debate fue rápidamente superado, pues "de otro modo se pondría en crisis el dogma de la unidad fundamental del género humano" (O’Gorman, 1995, p. 149); el problema que debía ser resuelto era el de su origen, que debía remontarse a Noé (Borja Gómez, 2002, pp. 139-141).

Para ingresar al curso de la historia, los indígenas debían pagar un precio: ocupar un lugar bajo en la humanidad y aceptar las imposiciones del modelo europeo. En otras palabras, borrar su diferencia, cambiar sus formas de vida (O'Gorman, 1995, p. 150). De esta manera queda clara la producción de una relación de excepción a partir de un discurso (la geografía) y una visión del mundo que busca la unidad (la interpretación de las diferentes comunidades a partir de un único origen -Noé- y de un único relato -el Cristianismo-, opera como principio trascendente y unificador que produce jerarquías) que, en consecuencia, aniquila la diferencia por considerarla como señal de inferioridad.

Por otra parte, el problema sobre el origen de los indios americanos que suscitó su reconocimiento como humanos, condujo a la formulación de diversas teorías acerca de los títulos de dominación de los españoles sobre los indios y de la forma como la Conquista debía llevarse a cabo, como se observa en las teorías sobre la guerra justa de Vitoria, Sepúlveda y Las Casas, las cuales fundamentaron las decisiones imperiales. En otras palabras, la geografía y la teología del siglo XVI -indisociables para ese entonces-, así como la concepción de lo humano, hacen parte de los elementos heterogéneos de los que el poder soberano imperial se 
sirvió para producir un espacio factible de dominación y justificar la aniquilación de millones de vidas, nudas vidas. La concepción de lo humano y su relación con la geografía no solo permeó las teorías de la guerra justa (de las cuales será necesario hablar en otra oportunidad), también fue la base para realizar acuerdos entre soberanos y construir a América como un espacio libre de derecho, donde toda violencia era posible, como se verá a continuación.

\section{La apropiación de América desde Europa: líneas de amistad y rayas de división}

Como ya Se mencionó, Agamben, en su Homo Sacer I, pone en evidencia la relación intrínseca entre biopolítica y poder soberano. Este último produce, a través de una decisión que es siempre una exclusión incluyente, un espacio abandonado por el derecho, susceptible a cualquier tipo de violencia. Sin embargo, el poder soberano no solo tiene un aspecto negativo (como tanato-politica), también tiene un aspecto positivo en la medida en que produce nuevos ordenamientos jurídicos y territoriales, así como nuevas distribuciones de los roles sociales. Sobre este punto en particular se citó la referencia que hace Agamben al nomos soberano de Schmitt, el cual es entendido también como un Ordung y un Landnhame. Esta lógica biopolítica del poder soberano, a la vez negativa y productiva, se hace inteligible a través de los mecanismos jurídico-políticos que se emplearon durante el siglo XVI por parte de los nacientes Estados europeos para apropiarse de los territorios americanos y que requirieron de una decisión soberana. Agamben señala la importancia que para la biopolítica tuvo el encuentro con América, cuando llama la atención sobre el anuncio hecho por Schmitt (de manera implícita y a pesar de su decisionismo) acerca de la relación entre ordenamiento jurídico y soberanía que muestra la forma como el "Nuevo Mundo" es construido como una gran zona de excepción. En palabras del italiano:

Una lectura más atenta [del nomos de la Tierra] revela, sin embargo, que esta proximidad [entre nomos y soberanía] está presente de forma más clara. [...] el autor muestra cómo, en efecto, el nexo entre localización y ordenamiento jurídico en que consiste el nomos de la tierra, implica siempre una zona excluida del derecho, que configura un «espacio libre y jurídicamente vacío», en el que el poder soberano no conoce ya los límites fijados por el nomos 
como orden territorial. Esta zona en la época del Ius Publicum Europeaum, corresponde al Nuevo Mundo, identificado con el estado de naturaleza, en el cual todo es lícito. (Agamben, 2010, pp. 52-53)

Las implicaciones de este pasaje han permanecido impensadas. Agamben no continúa esta línea de investigación sino que, de manera legítima, se circunscribe a pensar las transformaciones de la biopolítica en Europa. No obstante, los estudios sobre el derecho internacional permiten aclarar la forma como se produjo un espacio excluido del derecho para poder dominarlo, y cómo se posibilitó el proceso de colonización y de división global de la tierra en favor de los nacientes Estados europeos.

Dicho espacio libre y expuesto a toda violencia se construye -junto con los discursos racistas sobre lo humano- mediante actos jurídico-políticos; en concreto, a través de tratados celebrados entre las potencias europeas que trazan líneas ya sea para distribuir las zonas sobre las que un soberano puede ejercer su poder (estas son las llamadas "rayas"), o para marcar el límite a partir del cual cualquier cosa está permitida y el derecho suspendido (se trata de las denominadas amity lines). Dentro de estos tratados que, en palabras de Schmitt, evidencian y efectúan el segundo nomos o apropiación de la tierra y la primera división global de la misma, se encuentran el conocido Tratado de Tordesillas del 7 de junio de 1494, celebrado entre Portugal y España y confirmado por el Papa Julio II, y el Tratado de Cateau-Cambrésis celebrado entre España y Francia. Puede verse ahora en qué consisten estos y cómo opera en ellos la formación de una zona excluida.

Las líneas de amistad y las rayas producen una división de la tierra, si bien, existen grandes diferencias entre ellas. En primer lugar, las rayas son hispanoportuguesas, mientras que las líneas de amistad son, fundamentalmente, aunque no de manera exclusiva, franco-inglesas. En segundo lugar, la raya es acordada entre soberanos que comparten una misma religión (el catolicismo) y una misma autoridad espiritual superior (el Papa). Se trata, entonces, de soberanos que comparten una visión del orden del mundo, el cual se presupone dividido entre pueblos cristianos y no cristianos, con lo que las rayas manifiestan el fundamento identitario de las decisiones soberanas. De allí que lo que se acuerde entre portugueses y españoles sea la apropiación de tierra de soberanos y pueblos heterodoxos. Dicha apropiación implica, por un lado, la misión evangelizadora cuyo permiso es adjudicado por el Papa y, por el otro, la ocupación del territorio y el 
derecho al libre comercio, los cuales exceden la potestad del Sumo Pontífice (Schmitt, 2002, p. 60).

Por su parte, las amity lines son acordadas entre potencias que difieren en sus concepciones religiosas y que, por lo tanto, no reconocen un mismo poder espiritual (estos acuerdos se realizan entre Inglaterra, que es un reino protestante, y Francia y España, reinos católicos). Lo que caracteriza a estas líneas es que a partir de ellas se da lugar a la inaplicación del Derecho de Gentes Europeo en el espacio que se encuentra más allá de la línea, es decir, en los territorios "descubiertos". De esta forma se produce un espacio libre para la violencia: "queda vigente para esta época el principio de que los tratados, la paz y la amistad se refieren únicamente a Europa, es decir, al viejo mundo, al ámbito a este lado de la línea" (Schmitt, 2002, p. 62). Así, el historiador americano Francis G. Davenport muestra cómo los españoles se valieron de este principio durante el siglo XVII: "En ocasiones, aun los españoles hicieron valer su criterio de que los tratados vigentes en otros casos no eran válidos en las «Indias» puesto que aquello era un «Nuevo Mundo»" (Schmitt, 2002, p. 62). Esto posibilitó no solo la apropiación de territorios que tenían soberanos y que, en consecuencia, no podían ser adicionados si se les aplicaba el derecho de gentes europeo, sino también nuevas alianzas que, de no existir la zona de excepción creada por las líneas de amistad, implicarían un incumplimiento de acuerdos realizados entre potencias europeas. De este modo, por ejemplo, los franceses -que se habían aliado con los españoles en la lucha contra el protestantismo, es decir, contra Inglaterra fundamentalmente-, se unían con los ingleses, más allá de las líneas de amistad, para saquear ciudades españolas que se encontraban en la "Nova Orbis" (Schmitt, 2002, pp. 62-63).

La incorporación de estos nuevos espacios, es decir, de aquello que excede el orden vigente en Europa, supone el ejercicio de decisiones soberanas que operan de tal forma que, para anexarlos o incluirlos, lo primero que hacen es declarar la inaplicación del derecho europeo y solo después imponen leyes para los nuevos territorios que, en último término, son discriminatorias, excepcionales en comparación con el derecho que rige en Europa. Así, el estado de excepción, tal y como es definido por Agamben en Homo Sacer I, aparece acá con toda su fuerza: Europa mantiene los límites del uso de la fuerza señalados por el Derecho de Gentes solo al interior de Europa, y más allá de las líneas de amistad se abre un gran espacio en donde la norma se sustrae, quedando solo en vigencia "el derecho 
del más fuerte" (Schmitt, 2002, p. 63), un espacio libre en tanto allí se hace posible la aplicación "libre y desconsiderada de la violencia" (Schmitt, 2002, p. 64). Las reglas éticas, morales y políticas vigentes en Europa pierden toda aplicación en América y, simultáneamente, se asume que los indígenas se encuentran en un estado de naturaleza tal que deben ser guiados y dominados a nivel político y espiritual por los europeos.

A pesar de las diferencias entre líneas de amistad y rayas de división, ambos mecanismos jurídicos evidencian la construcción de un espacio que se excluye del derecho de gentes con base en presupuestos identitarios: pertenecer a una nación católica (rayas) o hacer parte del espacio europeo (amity lines). En este punto, lo que está en juego es una distribución del espacio con base en la pertenencia a los auto-denominados "pueblos civilizados", identificados con los pueblos europeos, un argumento que resuena con los actuales debates políticos y el derecho internacional público. En ello se evidencia la configuración de una forma de ejercer el poder mediante divisiones geográficas y valiéndose de argumentos racistas en los que opera la máquina antropológica. De modo que queda claro que el problema geográfico en la Conquista es un problema político y, en la medida en que implica una decisión soberana que construye un espacio libre de derecho, un problema biopolítico.

Mignolo reconoce la importancia de comprender las delimitaciones geográficas que operaron en el colonialismo y su relación con la configuración de -en términos agambenianos- una relación de excepción entre Europa y América, al afirmar que "[l]a geopolítica de la división continental es la clave para entender por qué «América Latina» fue incluida en Occidente y ubicada en la periferia al mismo tiempo" (Mignolo, 2007, p. 20). De manera similar, Foucault, en sus lecciones sobre la gubernamentalidad de 1977-1978 en el Collège de France, había recordado el papel estratégico que tuvieron las divisiones geográficas del siglo XVI y los tratados europeos del siglo XVII en una nueva configuración del poder y, también, el entrecruzamiento que a partir de ello se dio entre geopolítica y biopoder, aunque haya hecho referencia explícita a las líneas de amistad ni a las rayas. En términos de Foucault (2006):

La idea de «Europa» fue hecha de una forma completamente nueva al comienzo o en la primera mitad del siglo XVII (...). Europa no es una jerarquía de Estados en la que unos están subordinados a los otros, y que debía culmi- 
nar en la formación de un gran reino. (...) Europa es fundamentalmente plural (...). Pero Europa no es una pluralidad sin conexión con todo el mundo, y esta conexión marca el tipo específico de relación que tiene Europa con el mundo, a saber, una relación de dominio, de colonización, de opresión sobre el resto del mundo. Esta idea se forma al final del siglo XVI y comienzos del siglo XVII, idea que se concretiza a mediados del siglo XVII con una gran cantidad de tratados que se firmaron en aquella época. De esta realidad histórica no hemos salido todavía. Esto es Europa. (pp. 342-344)

Cuando en este pasaje Foucault habla de "tratados" se refiere, fundamentalmente, al tratado de Westfalia (1648) que dio origen al Estado-nación moderno construido sobre los principios de igualdad y de soberanía nacional. Como se sabe, este tratado solo era aplicable entre Estados europeos, pues América era territorio colonial. Lo que explica el autor francés es que el sistema supranacional en el que todos los Estados son vistos como iguales, surge a raíz del "Descubrimiento" de América, en donde España y Portugal lideraron el proceso de colonización. Posteriormente, en el siglo XVII, a raíz de las guerras de religión, se hace evidente la imposibilidad de las relaciones inter-estatales basadas en el liderazgo de las potencias católicas, por lo que es necesario el reconocimiento de todos los Estados como iguales, así como el asegurar la igualdad de fuerzas de todos los Estados europeos, evitando la formación de fuerzas imperiales como lo había sido España en el siglo XVI (Castro-Gómez, 2007, p. 163).

Si se tienen en cuenta los estudios de Schmitt sobre las líneas de división, amity lines y rayas, se puede decir que los tratados en donde ellas son consignadas fueron preparando el terreno para la formación de ese tratado en el que un nuevo orden global se concretiza, y también se puede adicionar que ellos no se dan al final del siglo XVI -como sostiene Foucault-, sino desde el comienzo mismo del Descubrimiento de América (1492). El “Descubrimiento" de América se configura, entonces, como el acontecimiento histórico que da lugar a una nueva configuración y concepción de lo político, de la forma de ejercer el poder que influye en nuestro presente. De hecho, Schmitt muestra (en una tesis similar a la que años después formulará Agamben) la estrecha relación entre este espacio libre y vacío que fue América, la martial law de los ingleses y la concepción de un comercio y una economía mundial libre. En palabras del alemán: 
La construcción inglesa del estado de excepción, la llamada «Martial Law», también está basada, de manera evidentemente análoga, en la concepción de un espacio delimitado, libre y vacío. (...) dentro de este ámbito local y temporal puede suceder todo aquello que, según la situación, parezca efectivamente necesario. (...) / Por otra parte, también las concepciones del mar libre, del comercio libre y de la economía mundial libre, con la idea de un margen libre para la competencia libre y la explotación libre, guardan una relación histórica y estructural con tales conceptos del espacio. (Schmitt, 2002, p. 70)

Es a partir de esta forma de pensar como se efectúa una biopolítica, en donde las nuevas tierras y sus habitantes son excluidos del Derecho de Gentes Europeo para ser incluidos en una máquina imperial con base en una supuesta superioridad de la civilización europea. Así, mediante decisiones soberanas excluyentes, se produjeron nudas vidas y un nuevo orden político y económico.

\section{Conclusiones}

LA INTRÍNSECA RELACIÓN ENTRE BIOPOLÍTICA Y SOBERANÍA, y la caracterización de esta forma de poder como (fundamentalmente) producción de la nuda vida que articula el bios (vida cualificada) y la zoé (vida biológica), es uno de los grandes aportes que Agamben realiza a la filosofía política. A partir de estos conceptos se ha podido avanzar en la comprensión de uno de los acontecimientos más importantes en la historia de Occidente y del mundo en general: la Conquista de América, develando los mecanismos que permitieron la dominación europea sobre todo un continente y la aniquilación con impunidad de millones de vidas y culturas. En concreto, vimos funcionar una máquina antropológica que clasificaba a los seres humanos según criterios como el logos para determinar su grado de humanidad y, en consecuencia, el trato que debían recibir. La concepción esencialista de lo humano de la filosofía aristotélico-tomista fue configurando un racismo donde operaba la lógica del poder soberano; esto es, la de una exclusióninclusiva. Así mismo, la geografía que se fue construyendo desde la antigüedad y a partir de tesis teológicas introdujo una jerarquía en la humanidad en donde Europa ocupaba el lugar más alto, seguido de Asia, mientras que África y América ocupaban los lugares más bajos. En el encuentro con América las formas de vida de los indígenas fueron excluidas, pues sus prácticas se veían como muy 
cercanas a lo corporal y a la manifestación de una desviación de la razón; al tiempo que se les incluía en un grado inferior de la clasificación de la humanidad, garantizando de esta forma su sujeción al poder imperial. Con todo, es posible sostener la tesis según la cual el racismo configura siempre una biopolítica, aunque no toda biopolítica sea racista (pensemos, por ejemplo en Foucault, que sostenía que la biopolítica surge en el siglo XVIII, pero reconoce que hay formas de racismo con anterioridad).

Por otra parte, las líneas de amistad y rayas acordadas mediante tratados en los siglos XV y XVI muestran cómo las decisiones soberanas construyeron, simultáneamente, un espacio donde toda violencia podía ser ejercida, además de una nueva distribución de la tierra a favor de Europa y la contribución a la creación de un nuevo modelo económico y político como lo es el colonialismo. En otras palabras, desde este punto de vista, la biopolítica puede ser pensada en su aspecto negativo (tanato-política) y positivo o productivo. Por esta razón, y siguiendo los aspectos conceptual y jurídico de la biopolítica, es posible decir que la Conquista constituye un paradigma de la biopolítica.

Por razones de espacio, no se ha explorado la forma como la biopolítica operó en los discursos intra-imperiales; esto es, en los discursos de la guerra justa emitidos por teólogos y juristas españoles. Sin embargo, interesante es concluir con una breve reflexión que abre el espacio a nuevas consideraciones para la arqueología del poder biopolítico. El punto de encuentro entre el nivel inter-imperial y el intra-imperial en la Conquista toma la forma de una contradicción entre los dos ámbitos, pues si España contribuye a la construcción de América como un espacio libre para la violencia mediante las rayas y líneas de amistad, al mismo tiempo, a nivel interno, reconoce la aplicación y vigencia del Derecho de Gentes en los territorios que se le adjudican. En tanto miembros de la humanidad -dirán los teóricos españoles de la guerra justa- los indígenas deben estar regidos por la ley natural y se les debe aplicar el derecho de gentes. Sin embargo, esto no implica la abolición de un poder biopolítico, ni la desaparición de una relación de excepción, sino que opera una mutación en el ejercicio del poder soberano: la guerra se justifica no porque haya un espacio libre de derecho, sino porque el derecho mismo legitima el uso de la fuerza. Este uso de la fuerza está en directa relación con el grado de humanidad que le es reconocido a los indígenas como lo muestran los discursos de Vitoria, Sepúlveda y de Las Casas. 


\section{Referencias}

Agamben, G. (2006). Lo abierto (Trads. E. Castro \& F. Costa). Buenos Aires: Adriana Hidalgo Editora.

Agamben, G. (2007). La obra del hombre. F. Lebenglik (Ed.), La potencia del pensamiento. Buenos Aires: Adriana Hidalgo Editora.

Agamben, G. (2009). Signatura rerum (Trads. F. Costa \& M. Ruvituso). Buenos Aires: Adriana Hidalgo Editora.

Agamben, G. (2010). Homo sacer. El poder soberano y la nuda vida (Trad. A. Gimeno Cuspinera). Valencia: Pre-textos.

Agustín de Hipona (1988). La ciudad de Dios. Tomo II. (Trads. S. del Río \& M. Fuertes Lanero). Madrid: Editorial Católica.

Aquino, T. (1950). Suma teológica. Tomo III. (Trad. F. Barbado Viejo O.P). Madrid: Editorial Católica.

Arendt, H. (2009). La condición humana (Trad. R. Novales). Buenos Aires: Paidós. Borja Gómez, J. (2002). Los indios medievales de Fray Pedro de Aguado. Bogotá: CEJA.

Castañeda, F. (2002). El indio: entre el bárbaro y el cristiano. Ensayos sobre la filosofía de la Conquista en Las Casas, Sepúlveda y Acosta. Bogotá: Universidad de los Andes/Alfaomega Colombiana S.A.

Castro-Gómez, S. (2007). Michel Foucault y la colonialidad del poder. Tabula Rasa, 6, 153-172. Disponible en línea en: http://www.scielo.org.co/scielo. php?script $=$ sci_arttext $\&$ pid $=$ S1794-24892007000100008\&lng=en\&nrm =iso. Consultado el 18.05.13.

Foucault, M. (2006). Seguridad, territorio, población: Curso del Collège de France (1977-1978). M. Senellart, F. Ewald \& A. Fontana (Eds.). Buenos Aires: Fondo de Cultura Económica.

Genel, K. (2004). Le biopouvoir chez Foucault et Agamben. Methodos. Disponible en línea en: http://methodos.revues.org/131. Consultado el 08.07.13. Jaúregui, C. (2008). Canibalia. Madrid: Editorial ETC.

Las Casas, B. (1988). Apología (Trad. Á. Losada). Madrid: Editora Nacional.

Lemke, T. (2005). A Zone of Indistinction. A Critique of Giorgio Agamben's Concept of Biopolitics. Outlines. Critical Practice Studies, 7(1), pp. 3-13. Disponible 
en línea en: http://ojs.statsbiblioteket.dk/index.php/outlines/article/view /2107/1871. Consultado el 18.04.13.

Mignolo, W. (2007). La idea de América Latina. La herida colonial y la opción decolonial. (Trads. S. Jawerbaum \& J. Barba). Barcelona: Editorial Gedisa.

O’Gorman, E. (1995). La invención de América. México, D.F.: FCE.

Platón (1999). Leyes (Trad. F. Lisi). Madrid: Editorial Gredos.

Quintana, L. (2006). De la nuda vida a la 'forma-de-vida': Pensar la política con Agamben desde y más allá del paradigma del biopoder. Argumentos, 19(52), pp. 43-60. Disponible en línea en: http://www.scielo.org.mx/scielo. php?script=sci_arttext\&pid=S018757952006000300003\&lng=es\&tlng= es. Consultado el 23.05.13.

Rojas, F. (2007). Caníbales en el paraíso: ideas clásicas sobre la Edad de Oro y la antropofagia en la etnología americana. F. Castañeda (Comp.), Francisco de Vitoria. Relección sobre la templanza o del uso de las comidas". Bogotá: Universidad de los Andes.

Schmitt, C. (2002). El nomos de la tierra (Trad. D. Schilling Thou). Granada: Editorial Comares.

Schmitt, C. (2009). Teología política (Trads. J. Conde \& J. Perez). Madrid: Editorial Trotta.

Sepúlveda, J. (1951). Demócrates segundo o de las Justas causas de la guerra contra los indios (Trad. Á. Losada). Madrid: Instituto Francisco de Vitoria.

Vitoria, F. (1946). Relección sobre los indios. Relecciones sobre los indios y el derecho de guerra (Trad. A. Pirotto). Buenos Aires: Espasa. 